\title{
'My Bedroom is me': Young people, private space, consumption and the family home
}

\section{Sian Lincoln \\ Introduction}

A bedroom in the family home is often regarded by young people as one of the first spaces over which they are able to exert a level of control, ownership and regulation and in which they can achieve some level of privacy away from the challenges of everyday life. It is a space that young people can call their own, can decorate according to their current tastes and can regulate in terms of who and who cannot enter that space. While bedrooms are in many ways functional spaces for young people, for example, they provide a space to sleep or do homework, they are also meaningful spaces that can tell us much about teenage life, youth culture and consumption. Bedrooms are worked upon, albeit at varying levels, and even when the space seems to change very little visually, the mere presence of a young person consuming within it, living out their social and cultural lives, means that it is a space that is never static. Moreover, for many young people, these are 'worked upon' spaces of identity and biographical display and representation, capturing both through cultural practices and the materiality of the space itself those often turbulent transitional years of growing up (Griffin, 1993; Roberts, 2008). Young people’s bedrooms are also quite complex spaces to understand, often spaces of contradiction. For example, as sites of consumption they can have a dual role as both spaces within which to stabilise and authenticate one's identity, as well as to play and experiment with it (Larson, 1995; Baker, 2004; Lincoln, 2012). They are spaces that can offer refuge at difficult times, but also spaces within which those difficult times can be experienced. They can be spaces to escape to, from the control and regulation of parents, but also spaces subjected to this type of regulation too (Heath, 1999, 2004). Bedrooms are spaces whose use is influenced by geographic location, familial formations, gender, social class and age, all of which are intertwined in often quite complex ways (James, 2001; Abbott-Chapman and Robertson, 2009; Lincoln, 2012). In addition to this, the meaning of a bedroom to a young person is changing in the context of the current UK economic climate. Government reforms such as the 'Housing Benefit size criteria’ (“Bedroom Tax”) for example, are prescribing how such private spaces can be used by a family often leading to multiple occupancy of a bedroom. Further, the parental home is increasingly being occupied by young people well into their twenties and way beyond the traditional youth period of one's teenage years. Biggart and Walther (2005) use the concept of 'yo-yo' transitions to understand young 
people's moves back into the parental home due to factors such as increased university fees, unemployment, cutbacks in welfare provisions and rising house prices that are rupturing traditional youth to adult transitions, even reversing them. In these instances the bedroom is more than just a transitional space but is site of permanence and stability amid a life trajectory that is anything but stable.

This chapter aims to get inside the often complex contexts of young people's uses of their bedrooms as spaces in the family home and as intimate sites of consumption, particularly in relation to their identities. 'Private' spaces like bedrooms take on a particular significance for the teenager that is different from other ages because they are experiencing their 'formative years' in which they are making key decisions about themselves and their future and defining who they would like to be (Larson, 1995). They are also times in which a young person feels in a perennial state of 'in-betweeness', in a state where they are precariously suspended inbetween different boundaries at home, school and at work as well as well as in leisure related contexts such as bars and clubs where their age might just be keeping them out but their peers are pressuring them to go in. In the midst of those times, private spaces such as bedrooms can play a pivotal role in young people’s lives because they provide a space for privacy, for intimacy, for respite, for the 'exploration of the self' a place to 'take stock' of their emerging adult lives and to think through these negotiations and dilemmas. However, the use of bedrooms by young people is subject to various 'layers' of regulation both inside and outside of the home, questioning the extent to which this is a truly private domain for the young occupant where they can 'be themselves': in which they can construct and consume their emerging identities. Similarly, the notion of 'private' space has become somewhat complicated for young people today as they find themselves entrenched in social media cultures whereby the boundaries of public and private become extremely blurred as Livingstone (2005), boyd (2014) and others have argued, or even ‘collapsed' (boyd, 2007; Marwick and boyd, 2010; Vitak, 2012).

In this chapter, I draw on ethnographic research data gathered for a project entitled 'youth culture and private space' (Lincoln, 2012) to understand how young people make private space meaningful to them. I explore how as spaces of consumption bedrooms represent the ways in which young people work through and between multiple boundaries inside and outside the home and how this shapes their emerging identities and young adult lives. In the following section I outline some of the key work on teenage 'bedroom culture' (for example, McRobbie and Garber, 1976; Larson, 1995; James, 2000; Lincoln, 2012) to establish the 
significance of private space in the family home and the meaning of spaces like bedrooms to young people in this context.

\section{Seeking self, seeking space: teenagers and their bedrooms}

The significance of bedrooms to young people as part of their everyday youth cultural lives is not a recent phenomenon. In their canonical paper Girls and Subcultures, Angela McRobbie and Jenny Garber (1974) questioned why teenage girls did not seem to be (at least according to accounts produced by the Centre for Contemporary Cultural Studies) participating in street-based youth subcultures. They argued that this didn't necessarily equate to their invisibility in street-based cultures but rather they argued that girls cultures were located and lived out in a different sphere: that of the domestic. In her later work (1991) McRobbie noted that girls' lives in the 1970s were:

...more highly structured than their male peers and their actions are closely monitored by the school, by youth leaders and by parents. The girls are firmly rooted in the home and local environment, and lack the social knowledge and expertise which derives from being able to visit and explore different parts of the city by themselves in the ways that boys can. (p.37)

In this respect, McRobbie argued, girls compensated for this lack of interaction in public spaces by 'creating culture based on each other, rather than on doing things together' (p.37, original emphasis) and this culture existed in their bedrooms. Girls additionally had to live their lives under the shadow of the 'double standard' (p.5): girls' reputations were everything and while they were seeking their male counterpart on the one hand, their interaction with boys in the public domain had to be carefully monitored. As McRobbie noted:

Girls had to be careful not to get into trouble and excess loitering on street corners might be taken as a sexual invitation to the boys.... Girls who spent too much time on the street were assumed to be promiscuous (p.5)

Girls were considered to be more at risk in public spaces 'from attack, assault or even abduction' and thus greater restrictions were placed on daughters than sons by parents (p.12). In addition, McRobbie noted that young girls also sought alternative ways of experiencing the leisure spaces they already inhabit (a theme that is evident in more recent accounts of girls using their bedrooms, see James (2000) discussed below). 
More recent studies of youth culture and the private domain, particularly from the mid-1990s onwards consider the significance of private spaces not just to young women but to young men too. This is because young people in contemporary times are growing up in environments that are readily defined as 'risky', globalised, neo-liberal and driven by practices of relentless consumption (Rose, 1999). Valentine and McKendrick (1995), Livingstone (2002) and others have argued that since the 1990s there has been a marked shift of young people's leisure activities back into the domestic sphere as public spaces like streets and parks become increasingly defined as unsafe for young people and as entertainment media become more diverse and competitively priced. In this respect, parents have been 'buying up' technology in an attempt to create leisure space in the home where they could keep an eye on their children.

Even more recently, studies of 'the private' in contemporary youth culture (that often draws on spatial metaphors such as the bedroom [see Lincoln and Hodkinson, 2008; Pearson, 2009; Robards, 2010; boyd, 2014]) have become of interest to academics. Social media have become ever-more ubiquitous in the lives of young people who are increasingly growing up in 'boundary-less' environments or environments of 'context collapse' (Marwick and boyd, 2010) which means that the dichotomies of public and private are no longer so clear cut and privacy takes on new meanings (boyd, 2014). As I have argued elsewhere (Lincoln, 2012), young people's bedrooms are not 'closed off' spaces confined to the domestic realm, but have become 'portals' from which young people can access a variety of different spaces and environments as they live out their everyday lives.

One of the consequences of this is young people's exposure to culture that doesn't just rely on what you 'go out and find' as described by McRobbie (1991); digital spaces don't require a physical presence in the public sphere (this is more a question of access to the technology). In this respect, it can be argued that private domestic environments like teenagers' bedrooms have become more complex because they can be infiltrated in a number of different ways. In this way, teenage bedrooms provide a microcosmic example of the layers of intervention and negotiation from public, private and virtual realms that take place in the domestic environment of the home and subsequently influence how that space is used and managed.

More recent studies of young people's bedrooms have focused on their meaning in the context of young people's emerging adult identities (for example, Larson, 1995; James, 2001; Lincoln, 2004; 2005; 2012).This is because as a child moves towards adolescence and their 
teenage years, he or she can experience a sense of 'in-betweenness' that pervades many aspects of their life that can make identities complicated or uncertain. For example, young people find themselves 'suspended' between adulthood and childhood, between dependence and independence, between public and private spaces (for example being too young to go to the pub while other peers start using similar environments), are starting to question the authority of parents and teachers but not necessarily being confident about the alternatives and so on. In this respect, spaces such as bedrooms offer a young person a place within which to work some of these uncertainties out, as well as giving them a space to work through the emotional, physical and psychological changes that come with adolescence too. This 'working out' is done in a number of different ways for example, through the materiality of the space (Lincoln, 2012; 2013), consumption of it and within it and through cultural and social practices. The bedroom can provide a 'canvas' to represent the interests, thoughts and feelings of the young occupant using the material resources available to them (Lincoln, 2012; Lincoln, 2014); can act as a 'portal' from which to communicate with others and engage in different (sub) cultural environments; and can be a social space in which to hang out with friends or a private space to escape from parents and siblings (Lincoln, 2012).

Kandy James (2001) pays attention to teenage bedrooms as 'alternative recreational spaces' for teenage girls in which they are able to resist social expectations or are a 'line of least enquiry' (p.72, original emphasis) in comparison to other public spaces such as swimming pools or other public recreational spaces. Drawing on interviews with girls aged 15 and 16 years old, James engages with what she defines in her earlier work (James, 2000) as 'situational body image' (p. 71) a concept that helps to explore the ways in which the girls in her study modified their bodies in particular social situations and what level of ridicule was associated to specific audiences and recreational spaces. James' study found that boys are much more likely to engage in sport-related recreational activities than girls. In these public contexts girls felt pressure to look or perform in a particular way that they were not necessarily comfortable with and, like the girls in McRobbie and Garber's (1976) study were vulnerable in public environments where potentially they could be ridiculed. For James' girls, the bedroom provided a space of their own that they could control (p.71). The girls' choice to use their bedrooms as sites of recreation were often the result of 'forced' choice; that is, private spaces such as bedrooms were deemed safe, a sanctuary, secure and a haven (p.78-79) in comparison to public spaces where they could potentially be judged, particularly in terms of appearance. James, like Larson (1995) below, notes that girls' use of private spaces such as 
bedrooms is particularly pertinent during the teenage years; as James puts it: 'adolescents are particularly vulnerable to embarrassment and are likely to avoid social situations or places where they perceive a potential for ridicule’ (p.73). For James’ participants, the bedroom was considered a 'site of emotions' for them (p. 78). As participant Laura put it 'if I have to cry about anything it's in my room', or Beth: 'if I'm really depressed I cry in there, that's where I have to go if I have to cry for anything...security.' (p.78). In addition, the bedroom was also a site of control for James’ participants 'at a time when many aspects of a girl's life were beyond their control, the bedroom seemed to be the one place where they could exert authority’ (p.79). The bedroom was a place from which they could escape authority too. For example, the girls spoke of retreating to their bedrooms when avoiding their parents, particularly mothers who would ask the girls to do household chores; control of bedroom space was interrupted by the chores that they (but not their brothers) were expected to do. If you could successfully hideaway in your bedroom then somebody else would be asked to do them.

The media also plays an important role in understanding the uncertainties of teenage life, providing a host of resources (film, television, literature, music) that can be drawn upon adding additional layers of meaning to bedroom spaces. Importantly, the consumption of that media is shaped by the spaces that young people use them in. In his work on adolescents' private use of media Reed Larson (1995) argues that bedrooms provide a crucial site for young people, especially those experiencing their teenage years. In this private domain teenagers can shut themselves away from family, friends and peers and can retreat from the stresses and strains of the outside world. Larson argues that spaces such as bedrooms take on new meanings and significance for young people experiencing these years. He argues that as they move into their adolescent years, young people are finding new ways of engaging with their cultural surroundings using cultural resources, for example those provided by the media as 'tools' with which to understand their emerging identities. He goes on to argue that as young people's engagement with media (for example, music) becomes more purposeful and their connection to particular songs becomes more pertinent because the lyrics or melody capture their teenage experiences, the role of private space also takes on a new significance. In this respect, media such as music is consumed in very specific ways in the private realm as a 'meaning-making' resource. Larson argues that 'it is in their solitary bedroom lives where media has some of its most significant functions...' (p.536). When a young person begins to experience the physical, emotional and sociological changes associated with adolescence, a 
medium such as music becomes a resource with which that young person can work through different aspects of their maturing selves: it can become a type of 'self-help’ tool. For example, the lyrics of a song become significant because they can be related to a personal experience: a young person associating a song with 'coming out' or breaking up with a 'first love'. In turn, the affection for a particular song may manifest further in private space, for example through a poster of the band or artist who has recorded the song adoring the bedroom walls.

In my work elsewhere (Lincoln, 2004; 2005; 2012; 2013; 2014) I have argued that young people's uses of media in their bedrooms can be understood through the concept of 'zoning' (for example see Lincoln, 2004, p.94). 'Zoning' refers to the ways in which young people navigate and organise their own private domains, making their space meaningful as their space in the family home. Zones in bedrooms are both physical and virtual arrangements of bedroom space. 'Zoning' refers to the ways in which a young person utilises the physical space of their bedroom as well as the materials, items and objects that fill it as expressions and performances of identity and how a young person expands the physical space by opening and closing other realms in public and virtual spheres, primarily using media technologies such as a sound system, television, DVD player, games console, laptop, iPad, Smartphone and so on. The use of this technology, that fills many young people's bedrooms as their parents attempt to keep them off the risky streets, are particularly useful 'identity marking' resources. Take for example, the music blasting out of a teenager's bedroom that vibrates throughout the house in the form of a dull (or not so dull) thudding created by the cranked up bass. Playing music loud not only takes 'bedroom culture' outside the private realm of this space, spilling into other parts of the household, irritating parents and siblings alike, but it also signifies a statement of who the young occupant is and what their current tastes are. Playing music loud can be a form of rebellion if it is interrupting an otherwise quiet household. This can take on a further dimension if the bedroom window is open and the street is also subjected to the loud noise; that young person's musical choices become publically heard. Conversely, music can be 'zoned in' to be a highly private experience. Again, media technology facilitates this, for example through the use of an iPod or other mobile listening device or headphones plugged into a phone. In this respect, music is used to completely internalise the listening experience. Lying on the bed, listening to music through headphones is an intense, intimate experience. This intimacy can be experienced with another should headphones be shared, but the point is, this is a very individual and personal experience 
dictated by the feelings and emotions of the listener at that time. 'Zoning' then, is one way of conceptualising how young people manage a personal and private space that is subject to a range of invasions and interruptions as a room in the family home. Being in their bedrooms affords teenagers greater privacy than perhaps other parts of the house, although as I will explore in the next section of this chapter, this 'privacy' and the production and consumption of identity within it exists within the context of often quite complicated family politics as well as within the wider contexts of young people's youth cultures. What these studies collectively reinforce is the significance- and shifting meaning- of private spaces to young people transiting through their teenage years as critical sites within which the exploration of emerging identities can be explored through consumption, and how the production of a 'bedroom culture' by teenagers (primarily, but also by siblings and parents as will be discussed below) facilitates and regulates these identity-seeking practices.

\section{(Bedroom) space invaders}

Young people's consumption practices in bedrooms are not straight forward primarily because they are spaces in the parental home that are shared with other family members and thus those practices can be distorted in a number of ways and regulated by others' positions and roles in the home. Bedrooms are not just entered into by their 'owners'; they can be 'invaded’ by parents, siblings, friends or peers. This means that young people's bedrooms can take on different meanings, depending on who is and who is not occupying them and the extent to which the 'privacy' of that space is contained within the bricks and mortar of the home. According to my research, parents and siblings regularly invade a bedroom (Lincoln, 2012). Siblings, for example, may go 'snooping' into their brothers' or sisters’ bedrooms when they are not in; rifling through their 'stuff', retrieving things that belong to them, borrowing clothes or music, going in to get the shared games console or other piece of kit that has otherwise been monopolised (McNamee, 1998). Going into an older siblings' space when they are not there serves as a rite of passage for the younger sibling. Crossing the boundaries of a space from which they might ordinarily be excluded or restricted, as well as transcending the affordances of their age to reclaim items that are supposed to be shared, such as a games console or to borrow items such as clothes without permission gives the consumption of these goods a new significance. This consumption represents a challenge to age-related hierarchies in the sense that the younger sibling does not have to negotiate with their older sibling in order to access these things and their enjoyment of them is enhanced through the crossing of age and space boundaries. Further, taking these items into their 
bedrooms represents a claim to ownership even if this is only temporary and until they are discovered by the older sibling only to be taken back into their space.

Parents go into their children's bedrooms too. The frequency of entry and the reasons for it can vary but often it is mothers who would go in and clean the room, pick up laundry or retrieve crockery as well as have input on how the room is decorated and fathers who tended to have more of a say in how the space is regulated, for example in terms of who was and who was not granted access, especially for teenage girls (Lincoln, 2012). Bedrooms can also be 'invaded' by parents for reasons other than practical ones, for example, if they are curious about what their illusive son or daughter is up to. A number of my participants were aware of that sort of 'snooping' happened when they were not at home and thus they would hide things like bottles of alcohol, cigarettes, condoms or pornographic magazines and films inside cupboards, in the back of the wardrobe, in drawers, in among box files for college and so on, in the hope that they wouldn't be easily found (Lincoln, 2012). As with the example of siblings above, the fact that these items are hidden away from parents makes the consumption of them in bedrooms even more significant. Their consumption represents a challenge to (domestic) authority; doing things your parents have told you not to-under their roof. It represents a negotiation of time and space (inasmuch as young people find ways of consuming such items so that they remain undiscovered although this is somewhat complicated by the consequences of their consumption- for example smell of smoke or alcohol). This consumption also serves as a stamp of a young person's identity on their bedroom space as well statement of their ownership and control of it. However, as I will discuss below hiding things in bedrooms might not always be so straightforward, particularly if parents regulate content. Bedrooms can be 'invaded' for other, more serious reasons too. For example if parents have serious concerns about their child's welfare (they suspect he or she is drinking alcohol excessively, is smoking or taking illegal drugs, has an eating disorder, might be pregnant or is being bullied) they might resort to entering their children's bedrooms to find clues.

Bedrooms can be opened up by their young occupants to friends and used as social spaces; an invasion that is more controlled and regulated (Hodkinson and Lincoln, 2008). Bedrooms can provide a space in which friends hang out before a night on the town, enjoying a few drinks and listening to music in preparation for the night ahead. They can also provide a space to return to after a night out to dissect the night's events, wind down, perhaps enjoy a few more drinks and listen to music (Lincoln, 2004), continuing the consumption practices of their 
night out. The now ubiquitous use of social media, and particularly social network sites (SNS) mean that the bedroom can be opened up or 'zoned' out (Lincoln, 2012) even further to include those 'friends' who exist on sites such as Facebook or Twitter who can also participate in these post-night out consumption practices even if they are not physically in the same space. Uploading images of the night or 'tweeting' about the events of the evening take the social activities of friends in a bedroom out into virtual domains and thus their night out becomes an experience mediated by other peoples' experiences represented through images and text-based comments from the same night out. The bedroom is further mediated through music used to set the tone for the night ahead as well as to create the right ambience for coming down and chilling out from the night out (Lincoln, 2004).

A young person's bedroom then, is subject to various different invasions- some examples of which have been outlined here and many of which impact on the ways in which young people consume 'bedroom culture'. Sometimes the 'invasion' is controlled by the young people themselves, other times it is not. For the duration of this chapter, I wish to consider in more detail how consumption in 'private' space is managed by young people and how the intersections that these invasions create are worked though by a young person to create their own space. Referring specifically to three of my female participants Lisa, aged, 18 Sarah aged 12 and Lisa aged 14, I will explore how amidst all of this, the bedroom is a place where they can state 'this is me'.

\section{“Mum hates A Clockwork Orange”: Bedrooms, Identity and Parental Control}

For Lisa, aged 18 and a first-year student living in university halls of residence, her bedroom had always been an important space. When talking about this with Lisa, it emerged that its significance was related to a range of complex family issues that she has experienced while growing up. These experiences were primarily marked by the divorce of her parents when she was 6 , her mother meeting a new partner, then moving abroad when she was 14 years old, and her father also meeting a new partner. Lisa's mother had returned to the UK but was living in a different city to Lisa’s father. Lisa's mother had remarried and was living with her son (Lisa's younger brother) and stepson. Lisa's father had also remarried and was living with his wife and step daughter. There were periods of her life where Lisa had lived in both households, but the very nature of the situation positioned her as 'in-between' those two 
family formations; part of both but partial also. Lisa had a bedroom in both her mother and her father's house, but the concept of 'her bedroom' was quite different in each:

Well, I've got my own room at my mum's house in Carlisle but it's more of a guest room, but at my dad's, he still makes jokes that it looks like I never moved out, and there is just as much stuff [as there is in her room in halls] everywhere there ...

While Lisa did have a room in her mother's house, she described it as 'more of a guest room'. This suggested a certain amount of disconnection from the room, acknowledging that while she did have a space of her own it didn't really feel like it belonged to her, but rather it was a space that anyone who visited the house can sleep in. On the other hand, the room that she has in her father's house was very much her space and was a space that was left alone by her father, even when Lisa was away at university- it was still full of her things and she could literally walk into it at any time and engage in the activities she'd always done in there. This was significant in a number of ways not least because it constituted the difference between Lisa having her 'own room' in her father's home or sleeping in the 'guest room' when she goes to her mother's house as well as reinforcing the importance to Lisa of having a space of her own.

From an early age Lisa's mother had exerted control over what Lisa could and could not have in her bedroom and according to Lisa that has caused many battles between them over the years. Often these battles were over content and were media-related (for example, about types of music or particular films) as when Lisa's mother 'banned Marilyn Manson from her house and [she] hates a Clockwork Orange,' according to Lisa. While Lisa had interests in both (influenced by her mother's dislike of them) in her early teenage years, she had not been allowed to have any paraphernalia related to either in her room. Lisa had put up a Clockwork Orange poster on her bedroom wall, but her mother had regarded it as offensive and something that 'shouldn't be in her house', even if it was something that Lisa had an interest in, and demanded she took it down. Lisa explained that her reaction was also partly because she had a younger brother and her mother did not want him to see what she considered to be offensive imagery. Lisa's attempts to make her bedroom her own in this instance was intercepted by her mother and the offense she took to particular music and films. Lisa duly took down the poster knowing that she would be able to display it in her 'other' bedroom. 
According to Lisa, her father took a much more liberal approach than her mother to what Lisa could have in her room. Lisa said he:

didn't care - he's just painted my room and I decided to paint squares on one wall and stick things in the middle of the squares and he didn't care, he was just like 'if that's how you want it, that's how you can have it' kind of thing, he just let's me have it my way.

Lisa considered her room at her father's house to be 'her bedroom' because it was a space that she was allowed to do what she wanted with and a space that she knew her father also acknowledged as 'her space' through allowing her to decorate the room the way she liked. In her mother's house where she was often restricted in terms of what she could have 'on display' in the her room, Lisa did not feel a connection to the space regarding it as - and as her mother saw it - the guest room that she slept in when she visited.

Throughout my discussions with Lisa, it was clear to see that her life had been profoundly affected by the divorce of her parents, which had brought with it a sense of uncertainty into her family life and a 'diversity' in her family formation that she did not always find easy to deal with. For Lisa, then, the need to have her own space was very important because this represented consistency and stability, both of which Lisa desired. Being able to mark out her bedroom as 'her space' was paramount. It was a place in which she could deal with the emotions of growing up, like the girls in James' (2001) study discussed above, as well as the uncertainties that came with her sometimes unstable home life. This desire for consistency and stability was articulated primarily through the contents of her bedroom evident in both the room at her father's house and in her halls of residence where she later lived. Her bedroom at her father's house was, according to Lisa filled full of 'stuff'. A self confessed 'hoarder', Lisa explained how she held on to the 'clutter' because she saw anything from a receipt to a cushion as part of the fabric of who she was and the experiences she was encountering as she grew up. This 'hoarding' strategy meant that Lisa had a space that was literally full of things about her life. The fuller it got, the more permanent it became because the amount of things it in would be very difficult to move. Her bedroom in this respect literally became 'anchored' as her space in the home through her 'hoarding' of material possessions and a space in which her identity was 'brimming over': anyone who walked into that room know that it was Lisa's. This strategy was also employed when Lisa moved into hall of residence in her first year at university. 
While hall spaces tend to be very generic in terms of layout and furniture, Lisa selected items from her bedroom at her father's house with which she was able to 'recreate' her bedroom in halls. This involved the use of very mundane generic items such as a washing basket that Lisa had put in her university room in exactly the same place as she would find it in her bedroom at her father's. Photographs were also significant in this 'translation', particularly photographs of her family when her parents were still together, a period of 'stability' in Lisa's life that she held onto through collages of photos in her room. For Lisa, the meaning of her bedroom at university (a space outside both parental homes) was constantly informed by the reference point of 'when my parents were together'. This, she claimed, was one of the reasons she considered herself a hoarder: she liked to hang on to things and not let go of the past. At every point in Lisa's room there was a story to be told about a particular object or item, from the Elvis cushions that her mother had made for her to the homemade 'SpongeBob Square Pants' made by her brother. More often than not, these stories would be told within the context of the time when her parents were together which was a particularly important reference point for her when things were not going so well:

Ummm ... there is pretty much everything, from when my parents were still together, there's stuff from school and then uni ones obviously, there is just pretty much everything from every part of my life like my first day at School ... I think it’s because the people in the pictures, if I needed them they would be there for me and it brings back memories looking at old photos so if I am feeling lonely I can look at them and think well it wasn’t always like this so it won’t always be like it kind of thing it makes you feel a bit better about it.

The private space of Lisa's bedroom operates as a container that is filled with material possessions that may appear meaningless to others (a supermarket receipt pinned on her wall, for example) but are meaningful to Lisa, particularly in the context of a stable family life (the receipt represented the first groceries she bought at university - a mundane, yet usually family-related, activity). Items like photographs help Lisa to maintain a sense of stability in her otherwise turbulent life and her bedroom is the place that accommodates those items. They also help her to navigate new experiences and provide her with a point of focus should she need it. Importantly, these items are transportable so Lisa was able to take old photographs with her to university, but equally she is able to take photographs back home from university as she becomes more comfortable with these new experiences and feels a part 
of them. Lisa said she would take back photographs of her boyfriend or of nights out with friends as constant reminders of the good times she was having at university. She said that this was particularly important when staying at her mother's house because 'when I go home [to my mum's house] I like to have my uni things just to remind me that I'm not going to be under my mum’s watchful eye there!'

\section{"She thinks she's our mam": Bedrooms, Identity and Sibling Control}

Sara and Natasha, aged 12 and 14 years old, were sisters who shared a bedroom. They were two of five siblings living with their mother in a single parent household. Sara and Natasha got on well because they were relatively close in age with only couple of years separating them. However, in discussions with them, they talked about their more difficult relationships, particularly with their eldest sister and, to a lesser extent, with their young sister who was 8 years old. This discussion demonstrates the ways in which the girls used 'age' as a strategy to articulate their place in the home, particularly their bedrooms, to regulate content and to make sense of frictions within the broader household. As mentioned above, Sara and Natasha shared a bedroom but at the time of the research the eldest sister who was 18 years old was also using their bedroom as hers was being redecorated. As the girls spoke about how they all got on with each other it emerged that while an 'age' hierarchy was evident in their relationship with each other, the responsibilities that the eldest sibling took charge of within the home were a point of contention for Sara and Natasha, particularly as they were temporarily sharing a room with her.

Sara: The oldest one does our heads in, but the next one down [aged 17], she's all right.

SL: Do you argue a lot?

Sara: We both argue with the other one, the eldest one

SL: Why's that?

Sara: Because she thinks she’s our mam [mum].

Being the eldest of five siblings in a single parent family it seems reasonable that Sara and Natasha's sister would take on significant responsibilities in the family home, for example, she would do many of the domestic chores, cook for her siblings and look after them while her mother was at work. However, Natasha and Sara were not particularly sensitive to her plight and rather than supporting their sister in this role, saw her as an 'intruder' who they felt 
was pretending to be their mother. Natasha and Sara did not see her as worthy of her assumed adult status; instead, they preferred to see her as their sister, still within teen age and thus with little authority to tell them what to do. This 'rejection' was particularly emphasised when the girls talked about their eldest sister's use of their bedroom while her room was being re-decorated.

The girls' bedroom, already 'invaded' by their 8-year-old sister who liked to play in it and who had slowly introduced what Sara and Natasha called 'girly' pink toys into their space. Now it was being invaded again by their eldest sister. Sara and Natasha's room had just been redecorated and they had chosen a blue and silver colour scheme with accessories and furniture matching this scheme (hence the pink toys were not welcome). They endeavoured to keep it tidy (perhaps a novelty given its newness) and had storage space in which to keep all of their bits and pieces. Their eldest sister however would 'just throw all her college work all over the bed ... she has her homework and everything all over the bed ... and shoes ...' and, Sara added, 'I think that bed makes our bedroom look a mess'. So in addition to the girls being 'mothered' by their eldest sister, their space was also being ‘invaded' and according to them, disrespected by her through her frivolous throwing of items into the room , causing further tension and animosity between them. This was further exacerbated by the role of 'the boyfriend', Lee, the relationship with whom, Sara and Natasha felt, added to their sister's adopted 'mothering' role.

Sara: She’s got a boyfriend called Lee and she’s like ‘oh, I can’t go, I'm going out with Lee'

Natasha: We call her Mrs Lee, us!

SL: Does she bring him up to your room?

Natasha: No, not in our room ... oh, this is another thing. Say that we're downstairs watching telly or something before we're going to bed, if Lee comes in we've got to go upstairs.

On the one hand, the role of 'the boyfriend' is viewed by Sara and Natasha as just another way for their sister to establish her 'adult' mothering status, Lee is also used by her as a way to 'control' them and their use of the house. Like children, they were often 'banished' to their room so that their sister can be alone with her boyfriend which was especially important for her given that she didn’t have her own room, albeit temporarily, to have any privacy. But in 
scenarios such as this, the girls' bedroom moved from being 'their space' that they have spent time redecorating and making their own, to a space that they have been sent to like children: its meaning is different in this context because they have not chosen to use the space but have been forced to use it by their sister who they struggled to take seriously an as authority figure in their home. The girls' bedroom in this household then is a site of union, conflict and contradiction and its use is suspended within rather complex family dynamics and tensions among siblings. The room is shared in the first instance, but Sara and Natasha get on well. Their bedroom had already been redecorated and they had spent time thinking about decoration and colour schemes and had taken this as an opportunity to make a room that represented them as they both moved into their teenage years (for example they had painted the white furniture they already had silver). But at the same time as they were 'working on' their space and making it their own, it got invaded by their other siblings, for example their 8 year old sister who brings her 'childish' toys into the room and leave them there and their 17 year old sister who just 'dumps' things because it is not her room, just a place she is using for storage while hers in re-decorated. Finally, the room, despite being 'owned' by Natasha and Sara is used by their eldest sister as a way of exerting power over them, particularly when her boyfriend is visiting the house. Natasha and Sara then, are constantly trying to reclaim their own space.

\section{Conclusion}

So what does this tell us about young people, private space and consumption in the family home? First, the discussions above confirm that while a young person's bedroom is a space for basic functions such as sleeping and getting dressed, it is a space that plays an important symbolic role in the articulation of a teenage identity and of a sense of place in the home and beyond. As I noted in the introduction, young people’s use of private space is particularly significant because they are experiencing a period of growing up when not-quite-fitting-in is synonymous with the period of transition that the teenage years brings. In this respect, a young person's bedroom, which is often one of the first spaces that young people feel any sense of ownership over, takes on an important role as a site of meaning-making and identity marking. However, young people’s bedrooms exist within often quite complicated webs weaved through young people's interactions both inside and outside the home. In this respect, young people's uses of their bedrooms are caught up in a series of 'intersections' (Livingstone, 2005) whereby, on the one hand, they are using the space to work their way through different boundaries, regulations and restrictions across different spheres but, on the 
other, their use of private space is restricted, challenging the extent to which the young occupant can claim 'this space is me'.

Using the example of multiple and shared bedrooms, I have argued that young people experiencing their teenage years need private space in which to be themselves and to explore, construct and consume their own emerging adult identities. This need for space is influenced by a variety of factors that can be unique to different households. The dynamics of a family undoubtedly influences a teenager's use of their bedroom as well as the significance of it as a private space. Finding a space to call their own often involves negotiations with other family members; some members (mothers, fathers, older siblings) can even control its content, thus limiting, in the eyes of a teenager, the resources available to a young person to express their identity. Others have to 'find' space in a room that is shared or constantly invaded by other siblings and in such scenarios content and decoration become important symbols of ownership and identity.

Once in the bedroom, consumption within it occurs against a set of predefined criteria that in the scenarios above is determined by amongst other things: age, space and family relations. For example, items such as alcohol may be hidden in bedrooms and the fact that they are in a young person's bedroom does not by default mean that they will not be seen as parents and siblings can enter when the occupant is not around (therefore further privacy measures to hide such items are implemented to ensure they are not discovered). For this reason, taking those items 'out of hiding' to be consumed is in itself an act that reinforces the claim that 'my bedroom is me', is an act of rebellion and a signifier of growing up. While items may be hidden in bedrooms, so too can they be made more visible and taken out of one context to be consumed in another. The act of younger siblings invading bedrooms to borrow their older siblings' clothes demonstrates the new significance these items take when worn by the younger sibling in the context of their own room or even outside in the public realm. An example I elaborate on above is of siblings Natasha and Sara who were forced to share a room with their older sister while her bedroom was re-decorated. Fractures in their relationship occurred because of the older sibling's lack of consideration for Natasha and Sara's space. The 'just chucking things in' approach that she took to moving her stuff in temporarily represented a disrespect of their (newly decorated) room, messing up it up and disturbing the aesthetics that they had carefully considered. The temporariness of this move for the older sibling determined how she treated the space. In addition, their younger sister, 
desperate to share the space too, further dilutes the room's meaning when placing girly pink toys in the space.

Lisa's consumption practices were subject to multiple family formations and had to be adapted accordingly and in relation to different family contexts be it her mother's house, her father's or her room in halls of residence. Amidst these varying criteria that each context and formation presented, and in the quest to find stability in an often unstable life are Lisa's consumption practices that could be perceived as rather excessive to the extent to which she has so much stuff, it becomes difficult to move it - she is literally anchoring her identity through mass consumption. In working within the restrictions implemented by her father, mother or university, Lisa carefully manages her personal space exploiting the freedom she has in her father's house - the space which she considers to be the most authentic of her multiple bedrooms. These examples represent how consumption practices in private spaces such as bedrooms can be complex, negotiated, often pre-defined, constantly challenged, invaded and compromised for young people. However, while young people are working through the intersections of public, private and virtual life, the bedroom is a site where they can consume their identities and ultimately state 'my bedroom is me,' albeit with restrictions.

\section{Bibliography}

J. Abbott-Chapman and M. Robertson (2009) 'Adolescents' favourite places: redefining the boundaries between public and private space', Space and Culture, 12 (4), 419-34.

S.L. Baker (2004) 'Pop in(to) the Bedroom: Popular Music in Pre-Teen Girls’ Bedroom Culture,’ European Journal of Cultural Studies, 7 (1), 75-93.

d.boyd (2014) It's Complicated: The Social Lives of Networked Teens (New Haven: Yale University Press).

d.boyd (2007) 'Why Youth (heart) Social Networking Sites: The Role of Networked Publics in Teenage Social Life’, D. Buckingham (ed.), Youth, Identity, and Digital Media (Cambridge, MA: MIT Press), 119-42. 
C. Griffin (1993) Representations of Youth (Cambridge: Polity Press).

S. Heath (1999) 'Young Adults and Household Formation in the 1990s', British Journal of Sociology of Education, 20 (4) 545-61.

S. Heath (2004) 'Peer-Shared Households, Quasi-Communes and Neo-Tribes', Current Sociology, 52 (2), 161-79.

P. Hodkinson and S. Lincoln (2008) 'Online Journals as Virtual Bedrooms: Young People, Identity and Personal Space', YOUNG: The Nordic Journal of Youth Research, 16 (1) 27-46.

\section{K.A. James (2001) “"I just gotta have my own space!”: The Bedroom as a Leisure Site for Adolescent Girls', Journal of Leisure Research, 33 (1), 71-90.}

K.A. James (2000) “'You can feel them looking at you”: The experiences of adolescent girls in swimming pools', Journal of Leisure Research, 32 (2), 262-280

R. Larson (1995) 'Secrets in the Bedroom: Adolescents' Private Use of Media', Journal of Youth and Adolescence, 24 (5), 535-50.

S. Lincoln (2014) 'Mediated Private Space', A. Bennett and B. Robards (eds.) Mediated Youth Cultures: The Internet, Belonging and New Cultural Configurations (Basingstoke: Palgrave Macmillan), 42-58.

S. Lincoln (2013) 'Media and bedroom culture', D. Lemish (ed.) The Routledge International Handbook of Children, Adolescents and Media (New York: Routledge)

S. Lincoln (2012) Youth Culture and Private Space (Basingstoke: Palgrave Macmillan).

S. Lincoln (2005) 'Feeling the Noise: Teenagers, Bedrooms and Music', Leisure Studies, 24 (4), 399-414. 
S. Lincoln (2004) 'Teenage Girls’ Bedroom Culture: Codes versus Zones’, A. Bennett and K. Kahn-Harris (eds.) After Subculture: Critical Studies in Contemporary Youth Culture (Basingstoke: Palgrave Macmillan), 94-106.

S. Livingstone (2005) 'In Defence of Privacy: Mediating the Public/Private Boundary at Home', London. LSE Research Online, http://eprints.lse.ac.uk/archive/00000505, date accessed 05 May 2014.

S. Livingstone (2002) Young People and New Media: Childhood and the Changing Media Environment (London: Sage).

A. E. Marwick and d. boyd (2011) 'I tweet honestly, I tweet passionately: Twitter users, context collapse, and the imagined audience’, New Media \& Society, 13(1): 114-133.

S. McNamee (1998) 'The Home: Youth, Gender and Video Games: Power and Control in the Home', T. Skelton and G. Valentine (eds.) Cool Places: Geographies of Youth Cultures (London: Routledge), 195-206.

A. McRobbie (1991) Feminism and Youth Culture: From Jackie to Just Seventeen (Basingstoke: Macmillan).

A. McRobbie and J. Garber (1976) 'Girls and Subcultures’, S. Hall and T. Jefferson (eds.), Resistance Through Rituals: Youth Subcultures in Post-War Britain (London: Hutchinson and Co), 209-23.

E. Pearson (2009) ‘All the World Wide Web’s a Stage : The Performance of Identity in Online Social Networks’, First Monday, 14, (3), http://firstmonday.org/htbin/cgiwrap/bin/ojs/index.php/fm/article/view/2162/2127, date accessed 30 January 2012.

B. Robards (2010) 'Randoms in My Bedroom: Negotiating Privacy and Unsolicited Contact on Social Networking Sites’, Prism, 7 (3), 
http://www.prismjournal.org/fileadmin/Social_media/Robards.pdf, date accessed 30 January 2012.

K. Roberts (2008) Youth in Transition: Eastern Europe and the West (Basingstoke: Palgrave Macmillan).

N. Rose (1999) Governing the Soul: The Shaping of the Private Self (London: Free Associations Books).

G. Valentine \& J. McKendrick (1997) ‘Children’s outdoor play: Exploring parental concerns about children's safety and the changing nature of childhood' Geoforum, 28 (2), 219-235.

J. Vitak (2012) 'The impact of context collapse and privacy on social network site disclosures’, Journal of Broadcasting \& Electronic Media, 56(4): 451-470. 